\title{
Covid-19: Mental health services must be boosted to deal with "tsunami" of cases after lockdown
}

\author{
Ingrid Torjesen
}

London

Mental health should be a "core element" of the response to the covid-19 pandemic, with greater investment to cope with a predicted surge in cases after lockdown, say psychiatrists and the World Health Organization.

A survey by the Royal College of Psychiatrists of 1369 of its members at the beginning of May found that $43 \%$ were seeing an increase in urgent and emergency cases, including patients who had suicidal thoughts or were self-harming.

At the same time $45 \%$ reported a fall in routine appointments, suggesting that self-isolation, shielding, school closures, and fear of engaging with health services because of the risk of infection may be keeping patients away.

Wendy Burn, president of the Royal College of Psychiatrists, said, "We are already seeing the devastating impact of covid-19 on mental health with more people in crisis. But we are just as worried about the people who need help now but aren't getting it. Our fear is that the lockdown is storing up problems which could then lead to a tsunami of referrals.

"Mental health services will be at risk of being overwhelmed unless we see continued investment. The prevalence of mental health issues is also expected to grow enormously due to the repercussions of the virus and the lockdown on mental health."

\section{Groups at risk}

Tedros Adhanom Ghebreyesus, WHO director general, said that the effects of the pandemic on people's mental health were already extremely worrying. "Social isolation, fear of contagion, and loss of family members is compounded by the distress caused by loss of income and often employment," he said. "It is now crystal clear that mental health needs must be treated as a core element of our response to and recovery from the covid-19 pandemic.

"A failure to take people's emotional wellbeing seriously will lead to long term social and economic costs to society."

Groups at particular risk of mental health issues as a result of the pandemic include:

- Children and adolescents;

- Older people;

- People at risk of domestic abuse;

- People from lower socioeconomic groups and others who are hit hard financially;
- Frontline healthcare workers who have faced heavy workloads, life or death decisions, and risk of infection;

-Women, particularly those juggling home schooling with working from home and household tasks; and

- People with previous mental health or dependency issues, which will have been compounded by support groups having been unable to meet.

An analysis by the Centre for Mental Health, based on data from previous epidemics and the aftermath of the 2008 banking crisis, suggests that around half a million more people in the UK will experience a mental health difficulty over the next year as a result of the pandemic. ${ }^{1}$ If a second wave of covid- 19 occurs and the economy is damaged further the effects on mental health will be even greater and will last longer, it said.

\section{Natural response}

Data from a survey conducted by the Office for National Statistics from 20 to 30 March-as the lockdown started-show that almost half of the population of Great Britain (49.6\%) reported high levels of anxiety. ${ }^{2}$

Sarah Hughes, chief executive of the Centre for Mental Health, said that everyone was "finding life more stressful and anxious," which was the natural response to a major threat. "Most people's mental health will recover quickly when things improve. But for a significant number, the effects of the pandemic on their mental health will be serious and long lasting," she said.

The people most at risk were those "with the most precarious livelihoods, poorest health, and insecure lives in the first place," she added. "It is already clear that the pandemic itself is exacerbating health inequalities in the UK and globally. The mental health after-effects will most likely add yet more burden to those with the least resources, least power, and poorest health."

Centre for Mental Health. Covid-19 and the nation's mental health: Forecasting needs and risks in the UK. 15 May 2020. https://www.centreformentalhealth.org.uk/sites/default/ files/2020-05/CentreforMentalHealth_COVID_MH_Forecasting_May20.pdf.

2 Office for National Statistics. Personal and economic well-being in Great Britain: May 2020. 2020. https://www.ons.gov.uk/peoplepopulationandcommunity/wellbeing/bulletins/ personalandeconomicwellbeingintheuk/may2020.

Published by the BMJ Publishing Group Limited. For permission to use (where not already granted under a licence) please go to http://group.bmj.com/group/rights-licensing/ permissions 